\title{
Correction to: Recent advances in molybdenum disulfide-based electrode materials for electroanalytical applications
}

\author{
A. T. Ezhil Vilian ${ }^{1} \cdot$ Bose Dinesh $^{2} \cdot$ Sung-Min Kang $^{3} \cdot$ Uma Maheswari Krishnan $^{2} \cdot$ Yun Suk Huh $^{3}$ (D) $\cdot$ Young-Kyu Han $^{1}$
}

Published online: 1 April 2019

(C) Springer-Verlag GmbH Austria, part of Springer Nature 2019

\section{Correction to: Microchimica Acta}

https://doi.org/10.1007/s00604-019-3287-y

The original version of this article unfortunately missed Prof. A.T. Ezhil Vilian's project number in Acknowledgements. The missing project number is 2017R1D1A1B03034977. The correct acknowledgment is "We would like to thank the National Research Foundation grant funded by the Ministry of Science, ICT and Future Planning of Korea (No. 2014R1A5A1009799, 2017R1D1A1B03034977 and 2017M2A2A6A01020938) for funding support. We thank Seo Young Oh for her assistance with the drawing of schematic illustration and for sharing her wisdom with us during the revision of this research".

Publisher's note Springer Nature remains neutral with regard to jurisdictional claims in published maps and institutional affiliations.

The online version of the original article can be found at https://doi.org/ 10.1007/s00604-019-3287-y

Uma Maheswari Krishnan

umakrishnan@sastra.edu

$\triangle$ Yun Suk Huh yunsuk.huh@inha.ac.kr

$\triangle$ Young-Kyu Han ykenergy@dongguk.edu

1 Department of Energy and Materials Engineering, Dongguk University-Seoul, Seoul 04620, Republic of Korea

2 Center for Nanotechnology \& Advanced Biomaterials (CeNTAB), School of Chemical and Biotechnology, SASTRA Deemed University, Thanjavur, Tamil Nadu 613 401, India

3 Department of Biological Engineering, Biohybrid Systems Research Center (BSRC), Inha University, Incheon 22212, Republic of Korea 